\title{
The effect of vagotomy on the human gastrooesophageal sphincter
}

\author{
C. V. MANN AND J. D. HARDCASTLE \\ From the London Hospital and Medical College
}

There have been reports of oesophageal reflux following operations performed for peptic ulcer (Clarke, Penry, and Ward, 1965; Windsor, 1964). Reflux has been noted after partial gastrectomy (Windsor, 1964) and also after vagotomy plus a gastric drainage procedure (Clarke et al, 1965). The operation of vagotomy plus gastric drainage could cause reflux oesophagitis to occur either through direct damage to the gastrooesophageal sphincter and phrenooesophageal ligament or indirectly by its effects upon the stomach, eg, by causing gastric retention.

In this study, the possibility that vagotomy (plus a drainage procedure) performed for duodenal ulcer might damage the gastrooesophageal sphincter was investigated. The study also yielded additional information concerning the influence of the abdominal vagus nerves on the maintenance and control of gastrooesophageal sphincter pressures in man.

\section{MATERIAL}

Two groups of patients were investigated. The first group consisted of 15 patients each suffering from duodenal ulcer. All patients in this group had pre- and postoperative radiological studies of the gastrooesophageal junction and stomach which were normal. None of the patients suffered from symptoms of reflux oesophagitis and none had a hiatus hernia.

Preoperative pressure measurements of the gastrooesophageal sphincter were obtained in all 15 patients, and these studies were used as a control group with which to compare any postoperative changes in sphincter pressures.

Nine of these 15 patients were submitted to vagotomy, accompanied either by a pyloroplasty or by a posterior gastroenterostomy. The pressure studies were then repeated postoperatively as soon as a normal diet had been resumed; this was usually between the tenth and fourteenth postoperation days. The pressure measurements in these nine patients are reported as the 'early group'.

An entirely separate group of four patients was also studied. Like the first group, all these patients had normal preoperative studies of the stomach and gastrooesophageal junction. Each of these patients had undergone a truncal vagotomy plus a drainage procedure more than one year before the pressure tests, and were admitted for investigation of complaints of upper abdominal pain for which no basis in pathology was subsequently found. No pressure measurements had been taken in these patients before the original operation and the results of their pressure studies were compared with those obtained in the nine prevagotomy subjects of the early group. The pressure measurements in these four patients are reported as the 'late group'.

\section{METHOD}

Each pressure test consisted of measuring the pressures across the gastrooesophageal junction by fine waterfilled poly-ethylene open-tip tubes (ID $1.0 \mathrm{~mm}$ ) and small balloons $(1.0 \times 0.5 \mathrm{~cm})$ after the method described by Code and Schlegel (1958). Each unit that was passed consisted of two open-tip tubes and one balloon-tipped tube; the balloon and the orifices of the open-tip tubes were separated from each other by a distance of $5 \mathrm{~cm}$. Each of the water-filled systems was attached individually to a strain gauge manometer external to the patient, and after suitable amplification the pressure readings were translated by heated stylus pen writers onto waxed paper moving continuously at $6 \mathrm{~cm} / \mathrm{min}$.

In each test, after preliminary calibration the unit was swallowed by the patient into the stomach. Withdrawal pressure tracings were then recorded as the unit was slowly drawn from the stomach into the oesophagus by half-centimetre moves; at each move, both resting pressures and the response to a measured swallow of $5 \mathrm{ml}$ of water were obtained.

The recording system was sufficiently sensitive to register changes of pressure produced by respiration. Within the abdomen, inspiration was marked on the tracing by an upward (positive) deflection, while within the chest it was marked by a downward (negative) deflection. The point on the withdrawal tracing at which inspiration changed from a positive to a negative deflection was called the point of respiratory reversal and was taken to represent the diaphragmatic hiatus.

When analysing the results of each pressure tracing, pressures were plotted for each half-centimetre move as centimetres of water pressure above or below mean fundic pressure. The extent of the sphincter was delineated by that portion of the withdrawal tracing that possessed pressures greater than those obtained in the stomach and also showed relaxation and contraction responses to deglutition. At each move, both end-inspiratory and 
end-expiratory peak pressures were measured, and the results plotted separately.

The vagotomy procedure was always a bilateral division of the vagus trunks just below the diaphragm. Mobilization of the oesophagus was kept to a minimum, and no stitches were put in after division of the nerves to repair the phrenooesophageal ligament.

\section{RESULTS}

CONTROL GROUP The results in this group of 15 patients are shown (Tables I and II; Figs. 1 and 2). The pressures across the gastrooesophageal junction were similar to those reported by others (Atkinson,
Edwards, Honour, and Rowlands, 1957a; Botha, Astley, and Carré, 1957; Code, Creamer, Schlegel, Olsen, Donoghue, and Andersen, 1958; Code and Schlegel, 1958; Fyke, Code, and Schlegel, 1956) for the normal human gastrooesophageal sphincter.

By open-tip tube examination (Fig. 1) the sphincter was $2.0 \mathrm{~cm}$ long. The point of mean maximum endinspiratory pressure $\left(=12.6 \mathrm{~cm} / \mathrm{H}_{2} \mathrm{O}\right)$ was just below the hiatus, while the point of mean maximum endexpiratory pressure $\left(=7 \cdot 1 \mathrm{~cm} / \mathrm{H}_{2} \mathrm{O}\right)$ was just above the hiatus.

Only 14 balloon records were suitable for analysis. Pressures obtained by balloon (Fig. 2) were higher

TABLE I

RESULTS OF VAGOTOMY USING OPENING-TIP TUBE AT $\mathrm{cm} \mathrm{H}_{2} \mathrm{O}$

Abdomen

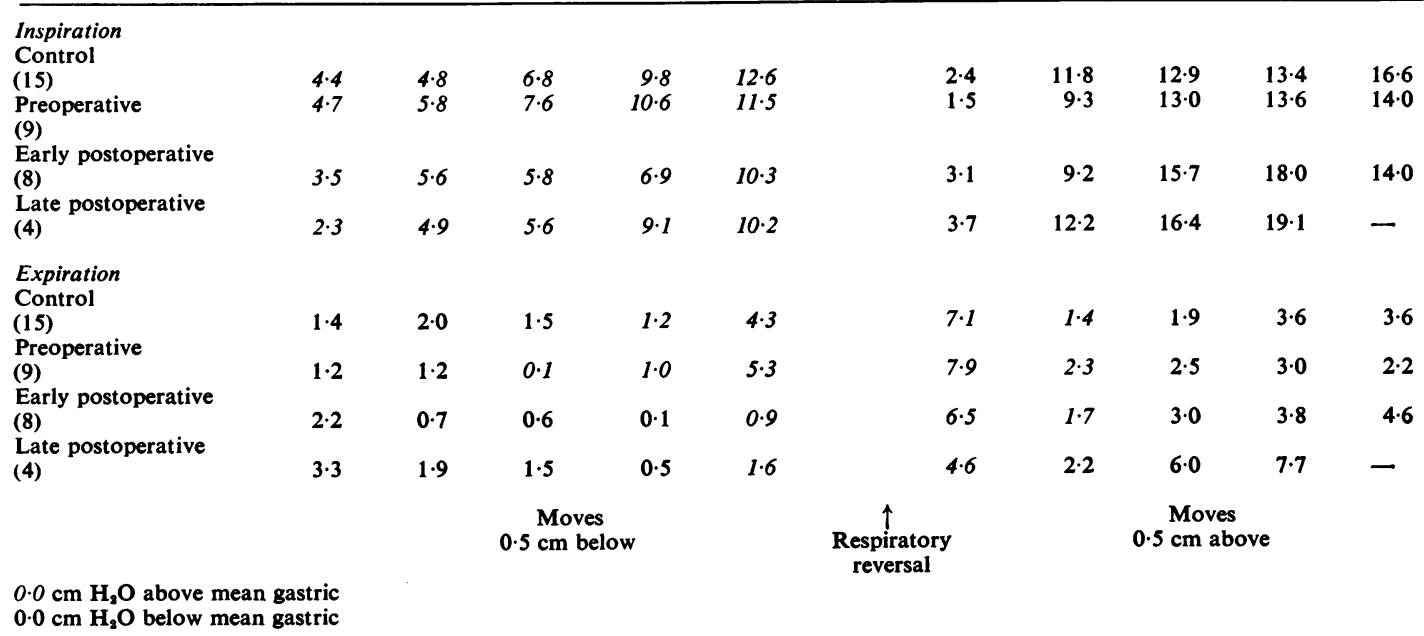

TABLE II

RESULTS OF VAGOTOMY BALLOON AT $\mathrm{cm} \mathrm{H}_{2} \mathrm{O}$

Abdomen

Thorax

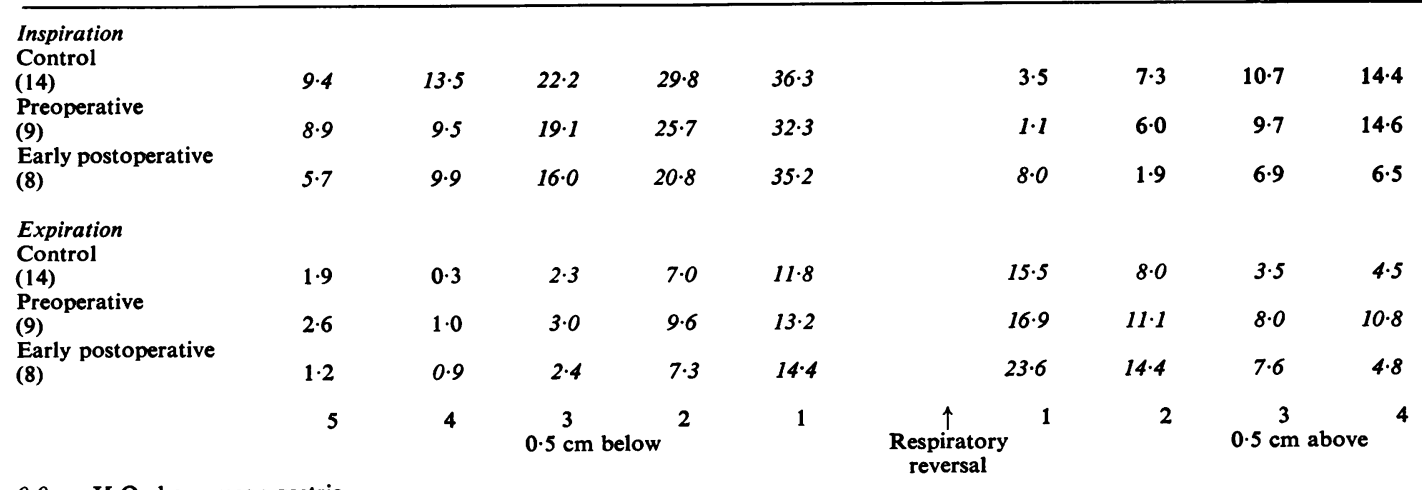




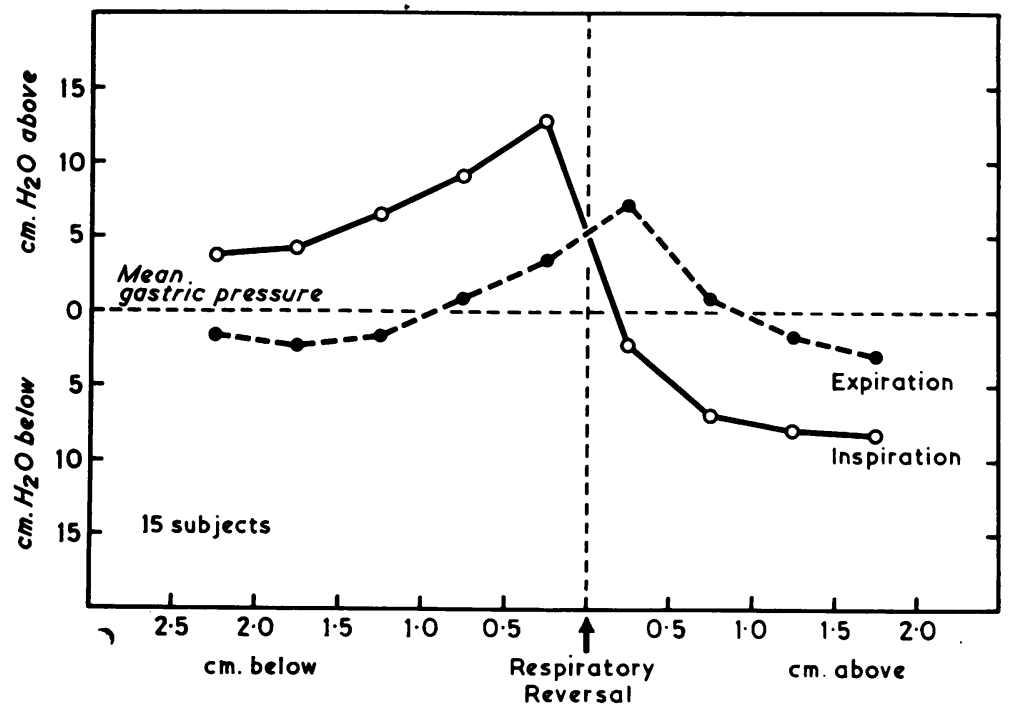

FIG. 1. Pressure profile of gastrooesophageal sphincter obtained by open-tip tube manometry in 15 duodenal ulcer subjects. The pressures at the half-centimetre moves just below and just above the point of respiratory reversal are the mean of 24 separate pressure measurements.

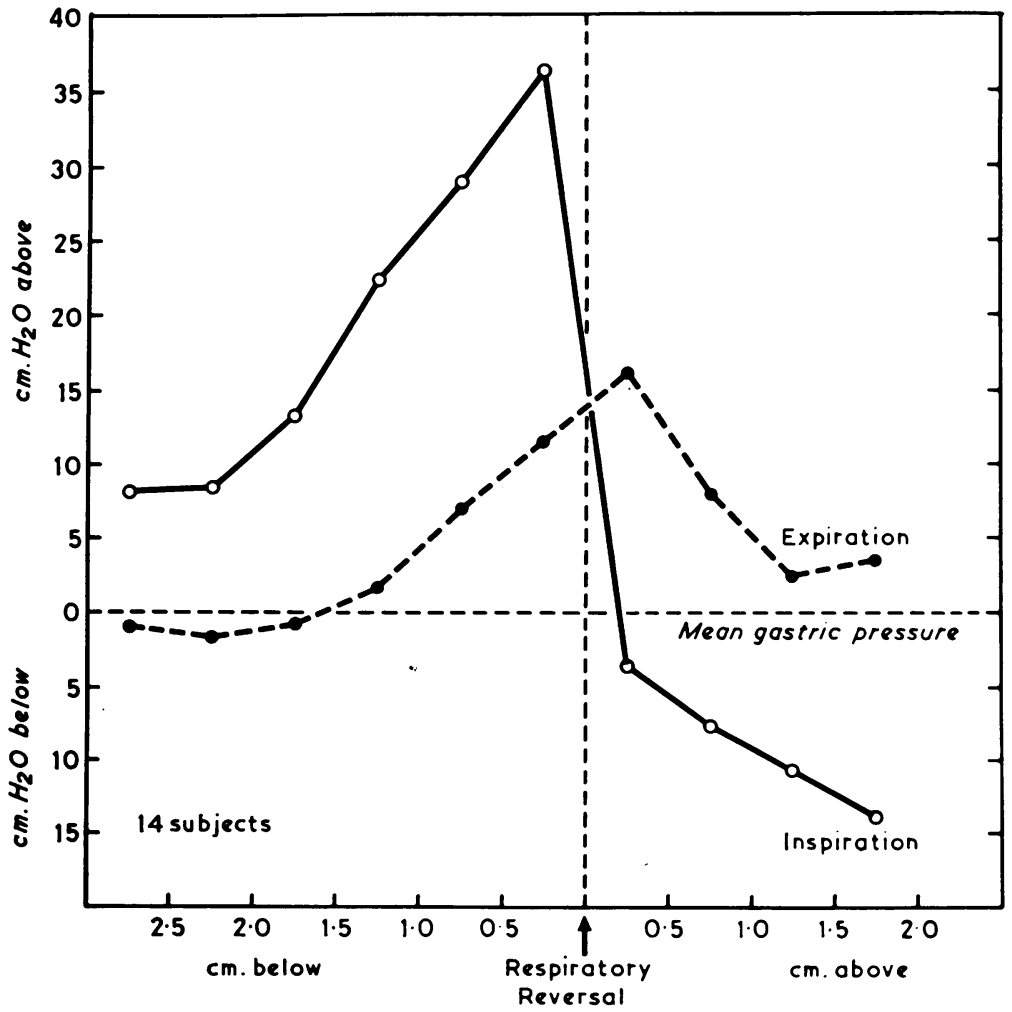

FIG. 2. Pressure profile of gastrooesophageal sphincter obtained by small balloon manometry in 14 duodenal ulcer subjects. The pressures at the half-centimetre moves just below and just above the point of respiratory reversal are the mean of 17 separate pressure measurements. 


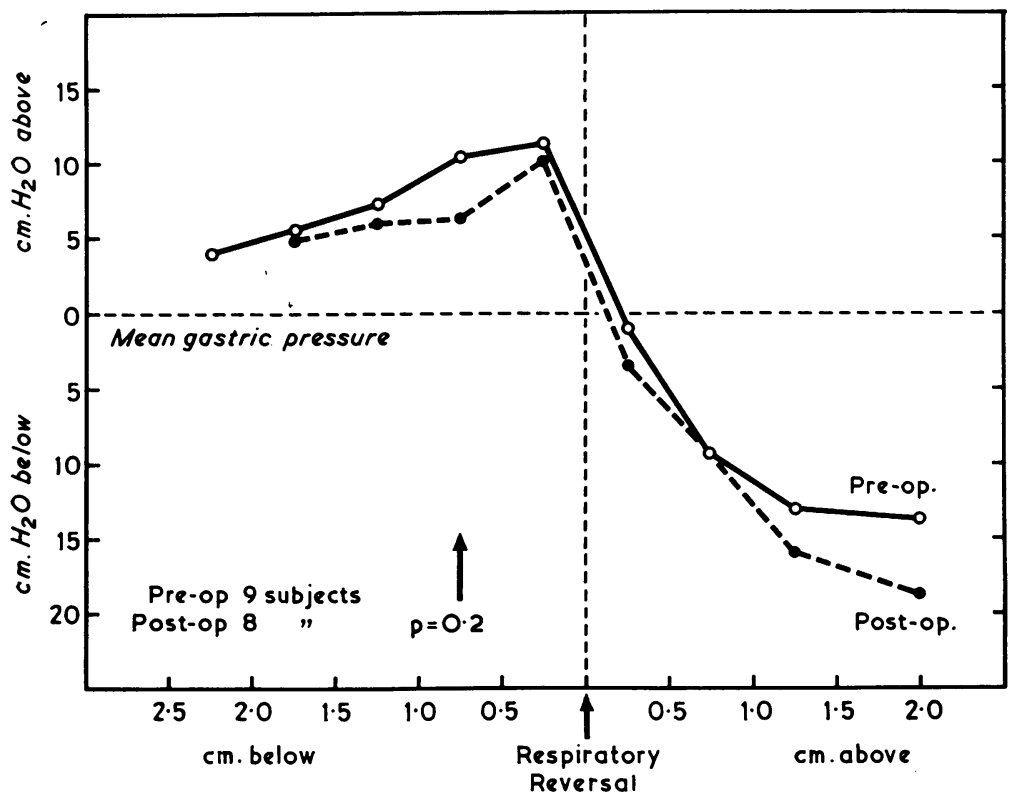

FIG. 3. Comparison of the prevagotomy with the early postvagotomy inspiratory pressure profiles of the gastrooesophageal sphincter obtained by open-tip tube in nine subjects. The pressures at the half-centimetre moves just below and just above the point of respiratory reversal are the mean of 15 separate pressure measurements in both tracings. A significant fall in postoperative pressure was found 1 centimetre below the diaphragm.

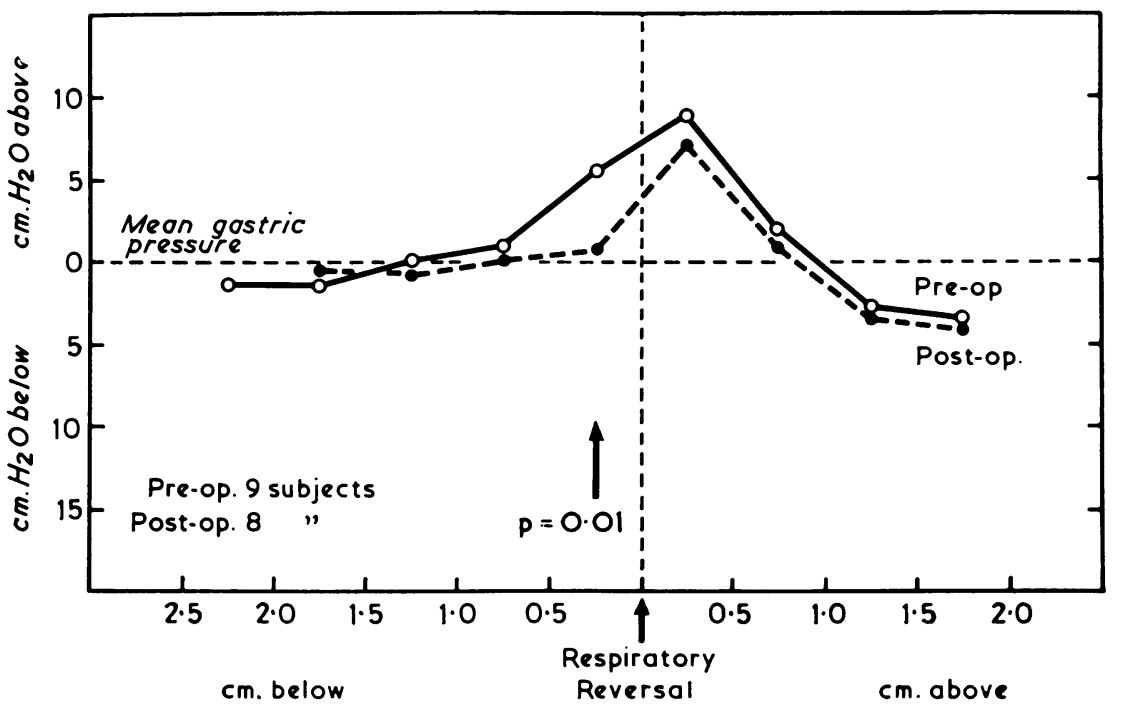

FIG. 4. Comparison of the prevagotomy with the early postvagotomy expiratory pressure profiles of the gastrooesophageal sphincter obtained by open-tip tube in nine subjects. The pressures at the half-centimetre moves just below and just above the point of respiratory reversal are the mean of 15 separate pressure measurements in both tracings. A significant fall in postoperative pressure was found half a centimetre below the diaphragm.

than those by open-tip tube. By balloon, the sphincter was $2.5 \mathrm{~cm}$ long. The mean maximum endinspiratory pressure point $\left(=36.3 \mathrm{~cm} / \mathrm{H}_{2} \mathrm{O}\right)$ was again situated just below the diaphragm, while the mean maximum end-expiratory pressure point $\left(=15.5 \mathrm{~cm} / \mathrm{H}_{2} \mathrm{O}\right)$ was just above the diaphragm.

Normal relaxation and contraction responses to each water swallow were obtained throughout the sphincteric zone.
EARLY GROUP The results in this group of nine patients are shown (Tables I and II; Figs. 3, 4, 5, and 6).

Satisfactory open-tip tube records were obtained in eight patients. The pressure measurements agreed closely with the control group, but reduced pressures were recorded postoperatively in both the endinspiratory and end-expiratory tracings just below the hiatus (Figs. 3 and 4). Peak sphincteric pressures 


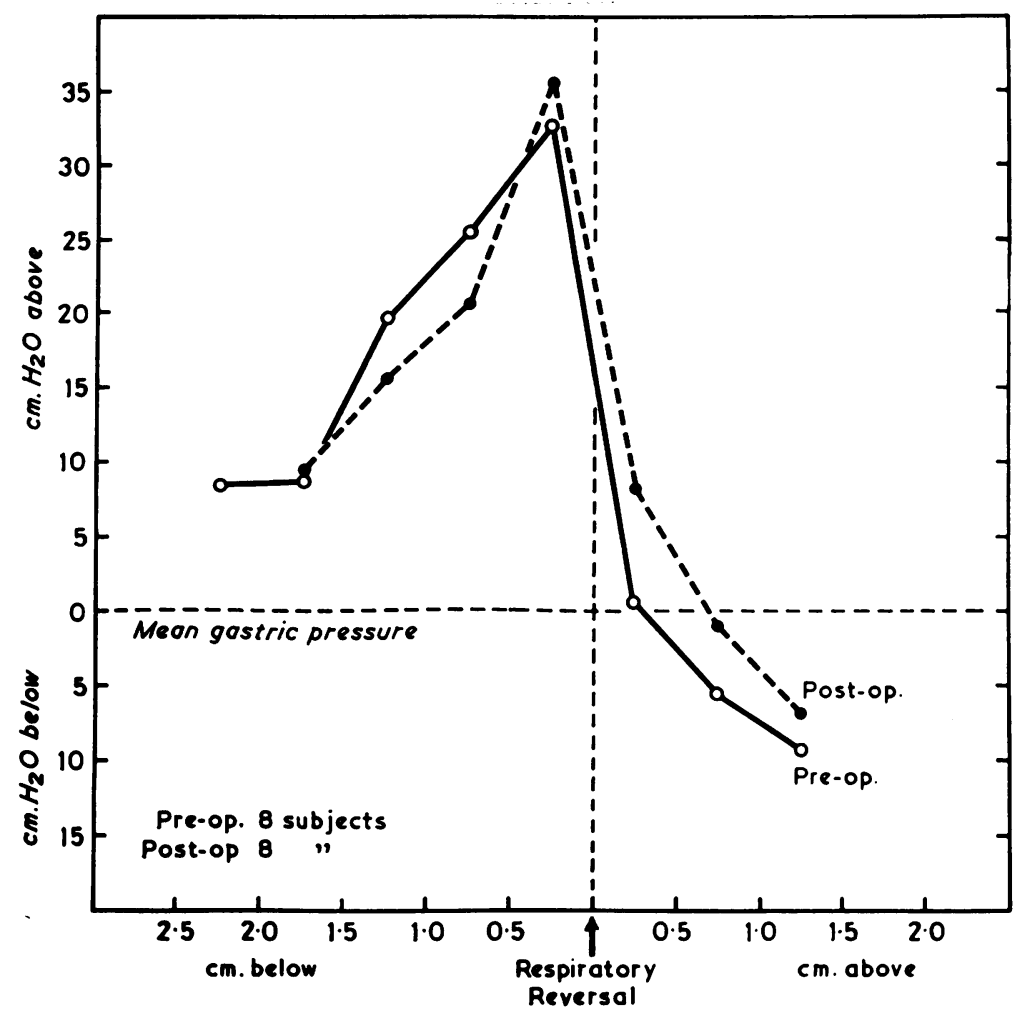

FIG. 5. Comparison of the prevagotomy with the early postvagotomy inspiratory pressure profiles of the gastrooesophageal sphincter obtained by small balloon in eight subjects. No significant postoperative pressure changes are demonstrated. The pressures at the half-centimetre moves just below and just above the diaphragm are the mean of nine separate pressure measurements in both tracings.

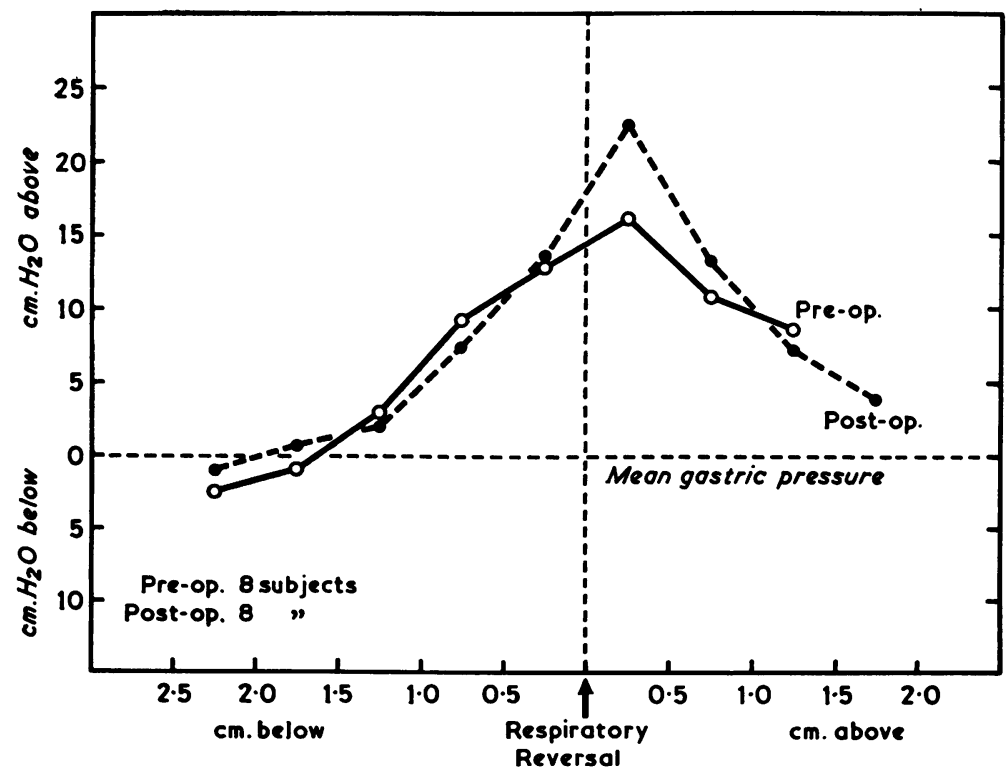

FIG. 6. Comparison of the prevagotomy with the early postvagotomy expiratory pressure profiles of the gastrooesophageal sphincter obtained by small balloon in eight subjects. No significant postoperative changes are demonstrated. The pressures at the half-centimetre moves just below and just above the point or respiratory reversal are the mean of nine separate pressure measurements in both tracings. 


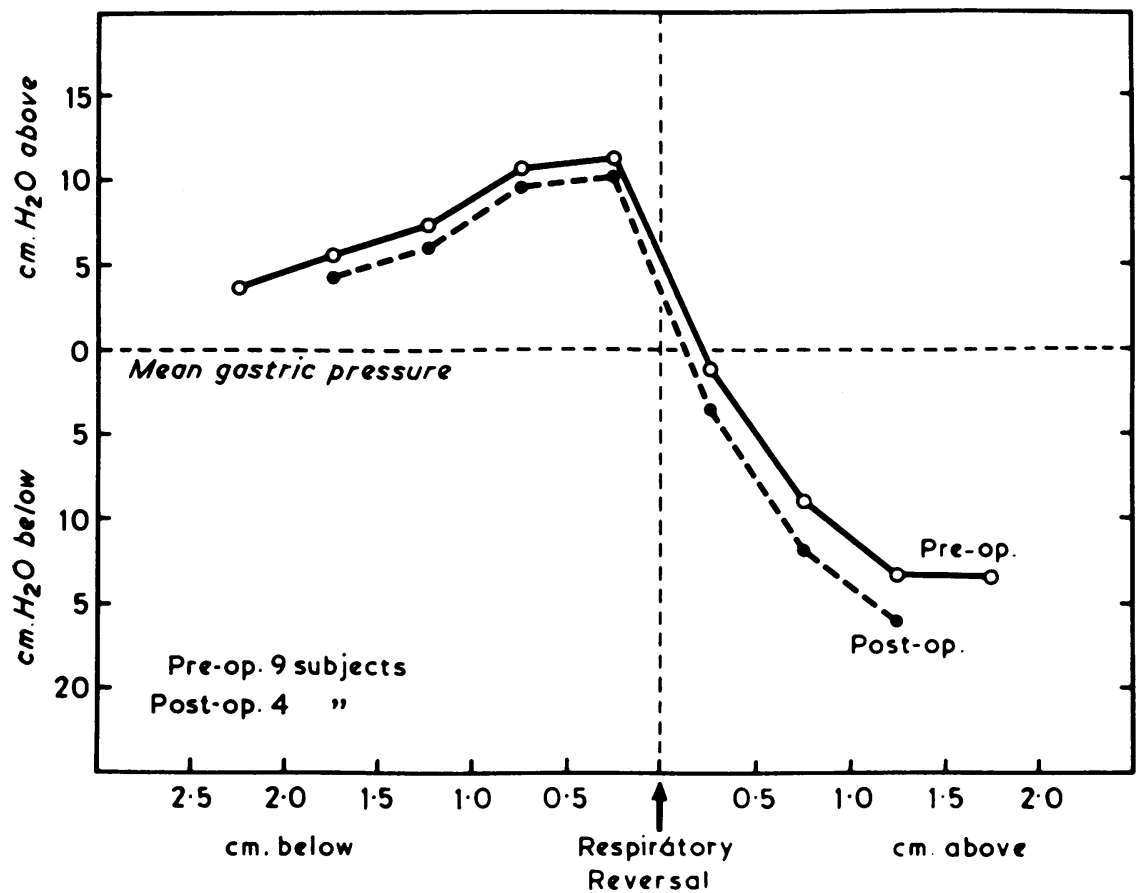

FIG. 7. Comparison of the late postvagotomy inspiratory pressure profile of the gastrooesophageal sphincter obtained by open-tip tube with the preoperative tracing obtained in the early group. Four subjects comprised the late group. Pressures in the late group at the half-centimetre moves just below and just above the point of respiratory reversal are the mean of eight separate pressure measurements. No pressure differences are shown.

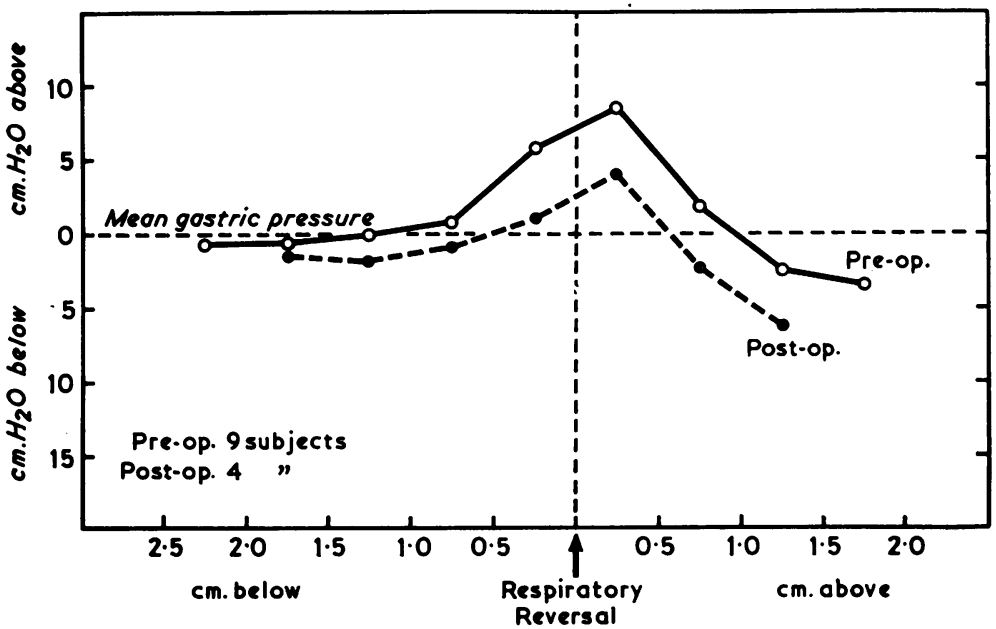

FIG. 8. Comparison of the late postvagotomy expiratory pressure profile of the gastrooesophageal sphincter with the preoperative tracing obtained in the early group. Four subjects comprised the late group. Pressures in the late group at the half-centimetre moves just below and just above the point of respiratory reversal are the mean of eight separate pressure measurements. Although the late postoperative pressures are generally lower, the reductions in pressure are not significant.

were unaffected by the operation but sphincter length was slightly shortened to $1 \cdot 5 \mathrm{~cm}$.

Balloon studies were not performed in one patient, but satisfactory studies were carried out in the remaining eight subjects (Figs. 5 and 6). No significant changes were found by comparison with the control group, although peak pressures were lower on the end-expiratory tracing (Fig. 6). Sphincter length was unaltered.

Normal relaxation and contracture responses to deglutition were obtained throughout the sphincter zone.

LATE GROUP The results in this group are shown 
(Table I; Figs. 7 and 8). Because of the very small numbers of patients studied, a suitable number of balloon records for analysis was not obtained in this group, and only the results of the open-tip tube studies are reported.

By open-tip tube examination (Figs. 7 and 8), end-inspiratory sphincter pressures were the same as those obtained in the control group. The endexpiratory pressure profile was generally at a lower level than that found in the prevagotomy group, but the reductions in pressure were not significant. Sphincter length was also shortened on the endexpiratory profile of the late group (Fig. 8), but was normal on the end-inspiratory tracing.

Normal responses to deglutition were present throughout the sphincter zone.

\section{DISCUSSION}

Examination of the sphincter pressures and swallow responses of both early and late postvagotomy groups revealed very few postoperative changes, and in all cases a definite pressure barrier remained at the gastrooesophageal junction. No changes in deglutition responses were ever observed after vagotomy. These findings do not support the view that reflux after vagotomy is due to damage to the intrinsic gastrooesophageal sphincter. Nor do they suggest that the abdominal vagus nerves have an important role in maintaining human gastrooesophageal sphincter pressures, which is in agreement with previous reports of distal vagotomy procedures in animals (Zeller and Burget, 1937; Hwang, Essex, and Mann, 1947; Carveth, Schlegel, Code, and Ellis, 1962; Greenwood, Schlegel, Code, and Ellis, 1962).

Although all patients in this investigation were duodenal ulcer subjects, the preoperative findings were very similar to those reported by others for the normal human gastrooesophageal sphincter (Fyke et al, 1956; Atkinson et al, 1957a and b; Botha et al, 1957; Code et al, 1958; Code and Schlegel, 1958), and it does not seem that the presence of a duodenal ulcer affects gastrooesophageal sphincter pressures. In so far as these subjects possessed greater than normal secretion of gastric hydrochloric acid before operation and reduced values afterwards, the absence of sphincter pressure change suggests that a low intragastric $p \mathrm{H}$ within the physiological range does not play a major role in controlling sphincter tone.

It is not clear from this study why a significant fall in sphincter pressure just below the hiatus was detected by the open-tip tube tests soon after vagotomy. It is not felt that this finding is an artefact since narrowing of the gastrooesophageal junction by oedema or fibrosis would be expected to cause increased pressures. Similarly, damage to the muscle would be expected to result in abnormalities of the contraction/relaxation responses to deglutition, yet such alterations in function were never observed. It is possible that damage to local vagal branches or the phrenooesophageal ligament (Michelson and Siegel, 1964) during mobilization of the oesophagus below the diaphragm is responsible for this early very localized point of postoperative fall in pressure. The findings obtained in the late group show that no significant permanent drop in sphincter pressure occurs as a consequence of vagotomy.

\section{SUMMARY AND CONCLUSIONS}

Gastrooesophageal sphincter pressures and deglutition responses were studied in duodenal ulcer patients after truncal abdominal vagotomy with a drainage procedure.

Postoperative changes were observed in an early group between 10 and 14 days after surgery and in a late group more than one year after surgery.

In the early group (nine patients) a significant fall of pressure immediately below the diaphragm was found by open-tip tube examination. No changes in sphincter pressure were found by small balloon studies, and deglutition responses were unaffected by the operation.

In the late group (four patients) no significant changes were found compared to control levels of sphincter pressure, and deglutition responses were normal.

The results of the investigation show that the reflux reported to occur after vagotomy is not caused by a fall in gastrooesophageal sphincter pressures as a consequence of the vagotomy procedure.

The reduction in sphincter pressure observed in the early group just below the hiatus may be a consequence of division of the phrenooesophageal ligament during mobilization of the lower oesophagus.

The minimal changes in sphincter pressures observed after vagotomy, and the absence of any alteration in deglutition responses demonstrate that the abdominal vagus nerves do not play a major role in maintaining or controlling the human gastrooesophageal pressure barrier.

We would like to acknowledge the encouragement of Professor Ritchie who allowed his patients to be used in this investigation, and made available the pressure recording equipment.

\section{REFERENCES}

Atkinson, M., Edwards, D. A. W., Honour, A. J., and Rowlands, E. N. (1957a). A comparison of the cardiac and pyloric sphincters. Lancet, 2, 918-922.

$\longrightarrow,-\longrightarrow,-(1957 \mathrm{~b})$. The oesophagogastric sphincter in hiatus hernia. Ibid., 2, 1138-1142. 
Botha, G. S. M., Astley, R., and Carré, I. J. (1957). A combined cineradiographic and manometric study of the gastro-oesophageal junction. Ibid., 1, 659-662.

Carveth, S. W., Schlegel, J. F., Code, C. F., and Ellis, F. H., Jr (1962). Esophageal motility after vagotomy, phrenicotomy, myotomy, and myomectomy in dogs. Surg. Gynec. and Obstet., $114,31-42$.

Code, C. F., Creamer, B., Schlegel, J. F., Olsen, A. M., Donoghue, F. E. and Andersen, H. A. (1958). An Atlas of Esophageal Motility in Health and Disease. Blackwell, Oxford. Thomas, Springfield, Illinois.

-, and Schlegel, J. F. (1958). The pressure profile of the gastroesophageal sphincter in man: an improved method of detection. Proc. Mayo Clinic, 33, 406-414.

Clarke, S. D., Penry, J. B., and Ward, P. (1965). Oesophageal reflux after abdominal vagotomy. Lancet, 2, 824-826.

Fyke, E. F., Jr, Code, C. F., and Schlegel, J. F. (1956). The gastro- esophageal sphincter in healthy human beings. Gastroenterologia (Basel), 86, 135-150.

Greenwood, R. K., Schlegel, J. F., Code, C. F., and Ellis, F. H., Jr (1962). The effect of sympathectomy, vagotomy, and oesophageal interruption on the canine gastro-oesophageal sphincter. Thorax, 17, 310-319.

Hwang, K., Essex, H. E., and Mann, F. C. (1947). A study of certain problems resulting from vagotomy in dogs with special reference to emesis. Amer. J. Physiol., 149, 429-448.

Michelson, E., and Siegel, C. I. (1964). The role of the phrenicoesophageal ligament in the lower esophageal sphincter. Surg. Gynec. and Obstet., 118, 1291-1294.

Windsor, C. W. O. (1964). Gastro-eosophageal reflux after partial gastrectomy. Brit. med. J., 2, 1233-1234.

Zeller, W., and Burget, G. E. (1937). A study of the cardia. Amer. J. dig. Dis., 4, 113-120. 